\title{
Calcitonin Gene-Related Peptide as a Biomarker in Migraine
}

\author{
Aktham Ismail Alemamª, , Wafeek Mahmoud Alsheikh ${ }^{\mathrm{a}}$, \\ Ibrahim Alsayed Alahmar ${ }^{\mathrm{a}}$
}

\begin{abstract}
Background: Migraine is a prevalent disease with much economic burden and relatively inadequate available treatment. Calcitonin gene-related peptide (CGRP) is the most abundant neuropeptide in the trigeminal nerve and it may be involved in the pathogenesis of migraine. The aim of the study was to determine the plasma level of CGRP in patients with primary headache, and if it could be a potential biomarker for migraine.
\end{abstract}

Methods: The study involved four groups with 20 patients in each one: chronic migraine, episodic migraine, cluster headache and tension type headache subjects, as well as healthy volunteers of matched age and sex as controls. Their venous blood was drawn, plasma was separated, and CGRP was analyzed with commercially available ELISA kit.

Results: Plasma CGRP levels were significantly increased in chronic migraine (165.0 $\pm 17.9 \mathrm{ng} / \mathrm{L}$, range 131.8 - 194.6) as compared with control group $(70.5 \pm 8.36 \mathrm{ng} / \mathrm{L}$, range $51.7-83.65)$, patients with episodic migraine $(94.1 \pm 17.83 \mathrm{ng} / \mathrm{L}$, range 69.6 - 121.9), and patients with cluster headache and tension type headache $(87.2 \pm 13.8$ $\mathrm{ng} / \mathrm{L}$, range 62.8 - 110.8). Plasma CGRP levels in chronic migraine were significantly higher in patients with aura (191.32 \pm 5.09 , range 185.45 - 194.60) than without aura $(160.30 \pm 14.93$, range $131.80-$ $186.0)$, and in episodic migraine were significantly higher in patients with aura $(109.88 \pm 7.54$, range $100.70-116.30)$ than without aura $(90.16 \pm 17.56$, range $69.60-121.90)$.

Conclusion: The plasma CGRP levels were elevated in patients with chronic migraine and may be considered a potential biomarker for it. This opens the door for a therapeutic role of it for migraine.

Keywords: Migraine; CGRP

\section{Introduction}

Migraine is the third most prevalent disease and one of the

Manuscript submitted October 30, 2017, accepted December 22, 2017

aDepartment of Neurology, Menoufia School of Medicine, Egypt ${ }^{\mathrm{b}}$ Corresponding Author: Aktham Ismail Alemam, Neurology Department, Menoufia School of Medicine, Egypt. Email: e_aktham@yahoo.com

doi: https://doi.org/10.14740/jnr460w most common seven causes of disability all over the world [1]. Its economic load is very high, with direct healthcare costs reaching several billions every year in the many countries [2]. The response rate to the currently available migraine abortive drugs does not exceed $60 \%$, in addition to the long list of adverse effects as the cardiovascular ones [3]. Also, the prophylactic medications for migraine were not designed for the treatment of migraine, and their use is often limited by their side effects or inadequate effect [4-6]. These facts may represent a wake-up call for new medications in migraine management [7].

Migraine is considered a neurovascular disease in which neural events lead to pain and further nerve activation [8]. The brain dysfunction involves both the peripheral and central constituents of the trigemino-vascular system leading to the release of inflammatory mediators that consequently result in propagation and prolongation of pain [9]. The most abundant neuropeptide in the trigeminal nerve is calcitonin gene-related peptide (CGRP), which is present in $35-50 \%$ of neurons in the trigeminal ganglia [10]. The CGRP is a 37 amino acid vasoactive neuropeptide that is widely distributed in the central and peripheral nervous systems, which is primarily localized to $\mathrm{C}$ and $A \delta$ sensory fibers [11]. The vascular events may lead to migraine, perhaps by sustaining CGRP synthesis and release and thus modulating nociceptor signaling to the brainstem [12]. The aim of this study was to detect ictal plasma CGRP levels in peripheral blood in chronic migraine as a potential biomarker for permanent trigemino-vascular activation.

\section{Patients and Methods}

\section{Patients}

The patients were selected from Outpatient Clinic of Neurology Department, Menoufia University Hospitals (from November 2016 to April 2017). This was a cross-sectional study that enrolled 80 individuals after obtaining their written informed consent and approval of Ethics Committee of Menoufia University Hospitals.

They were divided into four groups with 20 patients in each one. Group 1 included patients with chronic migraine (15 or more headache days per month for at least 3 months). Group 2 included patients with episodic migraine attack (fewer than 15 headache days per month). Group 3 included patients with cluster headache and tension type headache. Group 4 included persons who never had recurrent primary headaches and 
Table 1. Comparison Between the Four Studied Groups According to CGRP

\begin{tabular}{|c|c|c|c|c|c|c|}
\hline & $\begin{array}{l}\text { Chronic migraine } \\
(\mathrm{n}=20)\end{array}$ & $\begin{array}{l}\text { Episodic migraine } \\
(\mathrm{n}=20)\end{array}$ & $\begin{array}{l}\text { Tension type and cluster headache } \\
(n=20)\end{array}$ & $\begin{array}{l}\text { Control } \\
(n=20)\end{array}$ & $\mathbf{F}$ & $\mathbf{P}$ \\
\hline \multicolumn{7}{|l|}{ CGRP } \\
\hline Min. - Max. & $131.8-194.6$ & $69.6-121.9$ & $62.8-110.8$ & $51.7-83.65$ & $155.09 *$ & $<0.001 *$ \\
\hline Mean \pm SD & $165.0 \pm 17.9$ & $94.1 \pm 17.83$ & $87.2 \pm 13.8$ & $70.5 \pm 8.36$ & & \\
\hline Median & 167.38 & 97.0 & 86.95 & 70.63 & & \\
\hline
\end{tabular}

F: F value for ANOVA. Sig. between groups was done using post hoc test. $P_{\text {Control }}: P$ value for comparing between control and each group. $P_{1}: P_{\text {value }}$ for comparing between chronic migraine and episodic migraine. $\mathrm{P}_{2}$ : $\mathrm{P}$ value for comparing between chronic migraine and tension type and cluster headache. $P_{3}$ : $P$ value for comparing between episodic and tension type and cluster headache. *Statistically significant at $P \leq 0.05$. $F_{(3,76)}=2.725$.

in whom family history was negative for primary headaches (control group).

The patients are classified according to Headache Classification Committee of the International Headache Society (IHS). Patients did not take prophylactic therapy for at least 1 week before.

\section{Methods}

All subjects underwent complete general, neurological and psychiatric history and examination with more stress on analysis of headache: duration of disease, frequency of attacks per month, usual duration of untreated attack, headache characteristics, precipitating, relieving, and associated features.

\section{Laboratory tests}

\section{Estimation of serum CGRP}

CGRP level was determined by ELISA from blood samples obtained from the right antecubital vein at migraine attack and with the patient having taken no symptomatic medication the day before. Fasting venous blood $(3 \mathrm{~mL})$ was collected in a sterile EDTA vacutainer, at least 3 days after the attack of headache and the subjects were made to take rest for at least 2 $\mathrm{h}$ before drawing the blood. Sample was immediately centrifuged at 2,000 rpm for $3 \mathrm{~min}$ and plasma was transferred to another sterile clean vial to keep at $-70^{\circ} \mathrm{C}$ till further use. CGRP assay was done with the help of Human a-CGRP ELISA kits. After the test, absorbance was measured at $450 \mathrm{~nm}$ with the help of ELISA reader. Resultant readings were plotted against the standard curve to find out concentration of CGRP in each sample $(\mathrm{ng} / \mathrm{mL})$.

\section{Radiological evaluation}

All patients underwent a standard computed tomography (CT) and/or MRI scan of the brain to exclude other causes of headache. A neuroimaging specialist reviewed all the images.

\section{Statistical analysis}

Quantitative data were described using range (minimum and maximum), mean, standard deviation and median. Significance of the obtained results was judged at the $5 \%$ level. The used tests were: Chi-square test, Fisher's exact or Monte-Carlo correction, F-test (analysis of variance), Mann-Whitney test and Kruskal-Wallis test.

\section{Results}

We assessed plasma samples from all groups. Group 1 included 20 patients with chronic migraine, their age ranged from 20 to 56 years with mean age of $35.60 \pm 10.40$ years, $13(65 \%)$ patients were female and seven $(35 \%)$ were males. Group 2 included 20 patients with episodic migraine, their age ranged from 17 to 48 years with mean age of $33.05 \pm 10.44$ years, 14 $(70 \%)$ patients were female and six $(30 \%)$ were males. Group 3 involved 20 patients with either cluster headache or tension type headache, their age ranged from 18 to 52 years with mean age of $33.0 \pm 9.58$ years, $12(60 \%)$ patients were females and eight $(40 \%)$ were males. Group 4 included 20 subjects who never had recurrent primary headaches and in whom family history was negative for primary headaches, their age ranged from 24 to 53 years with mean age of $37 \pm 8.68$ years, 10 $(50 \%)$ patients were female and $10(50 \%)$ were males.

Plasma CGRP levels were significantly higher in patients with chronic migraine $(165.0 \pm 17.9 \mathrm{ng} / \mathrm{L}$, range 131.8 - 194.6) as compared with control group $(70.5 \pm 8.36 \mathrm{ng} / \mathrm{L}$, range 51.7 - 83.65, $\mathrm{P}_{1}<0.001$ vs. episodic migraine, $\mathrm{P}_{2}<0.001$ vs. tension type and cluster headache, $\mathrm{P}_{\text {Control }}<0.001$ vs. control), patients with episodic migraine $(94.1 \pm 17.83 \mathrm{ng} / \mathrm{L}$, range 69.6 - $121.9, \mathrm{P}_{1}<0.001$ vs. chronic migraine, $\mathrm{P}_{3}=0.471$ vs. tension type and cluster headache, $\mathrm{P}_{\text {Control }}<0.001$ vs. controls), and patients with tension type and cluster headache $(87.2 \pm 13.8$ ng/L, range $62.8-110.8, \mathrm{P}_{2}<0.001$ vs. chronic migraine, $\mathrm{P}_{3}=$ 0.471 vs. episodic migraine, $\left.\mathrm{P}_{\text {Control }}=0.004\right)$ (Table 1).

Plasma CGRP levels in chronic migraine were significantly higher in patients with aura (191.32 \pm 5.09 , range 185.45 - 194.60) than without aura $(160.30 \pm 14.93$, range 131.80 - 186.0). Also these levels in episodic migraine were 
Table 2. Relation Between CGRP and Aura in Each Group

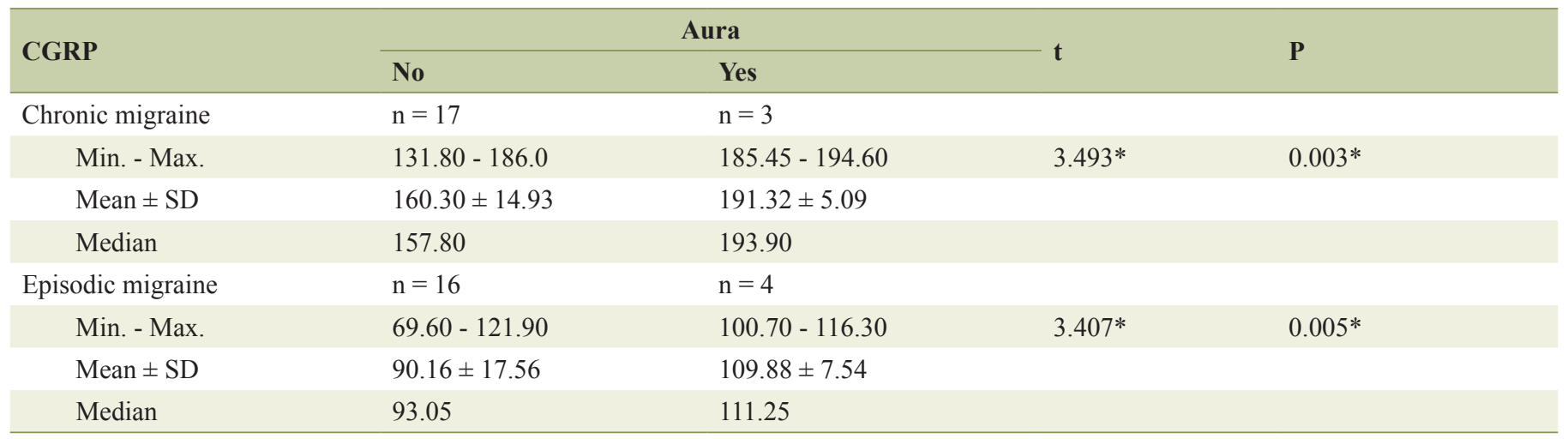

t, $P$ : $t$ and $P$ values for Student's $t$-test for comparing between the two groups. *Statistically significant at $P \leq 0.05 . T_{(18)}=2.101$.

significantly higher in patients with aura $(109.88 \pm 7.54$, range 100.70 - 116.30) than without aura $(90.16 \pm 17.56$, range 69.60 - 121.90) (Table 2).

There was no statistically significant difference between plasma CGRP level and either the age of patients, severity of headache attack, frequency or duration of attacks (Table 3).

\section{Discussion}

Our study found that as compared with healthy people without a history of headache, ictal period CGRP levels were clearly elevated in peripheral blood in patients with chronic migraine and, to a lesser degree, in patients with episodic migraine, cluster headache and tension type headache. CGRP levels in either chronic or episodic migraine were significantly higher in patients with aura than without it.

In agreement with our results, Cernuda-Morollon et al [13] found that the plasma level of CGRP was increased during the migraine attack. It returned to the normal after giving the triptans to the patients and stoppage of headache. Also, Larrosa et al [13] and Goadsby et al [14] found that during the phase of headache of migraine, the plasma level of CGRP measured in the jugular vein is increased while other neuropeptides did not. Hansen et al [15] postulated that giving human CGRP induced a migraine attack in susceptible individuals. The CGRP levels returned to baseline after management of migraine.

While Cernuda-Morollon et al [13] found that the increase in plasma CGRP levels during migraine attacks was significantly correlating with the headache intensity, our results showed that this correlation was not present. Additionally, Fusayasu et al [16] proved that the inter-ictal level of CGRP was not increased in the plasma only, but also in the saliva of the patients with migraine. These studies may suggest that trigeminal CGRP release is a reliable marker for migraine that can be measured in a venous blood sample, and the decline in its level may predict antimigraine effect [17].

On the other hand, Tvedskov et al [18] did not find any increase in plasma CGRP levels during migraine attacks. In this negative study, the researcher visited patients at their home or

Table 3. Correlation Between CGRP and Different Parameters in Each Group

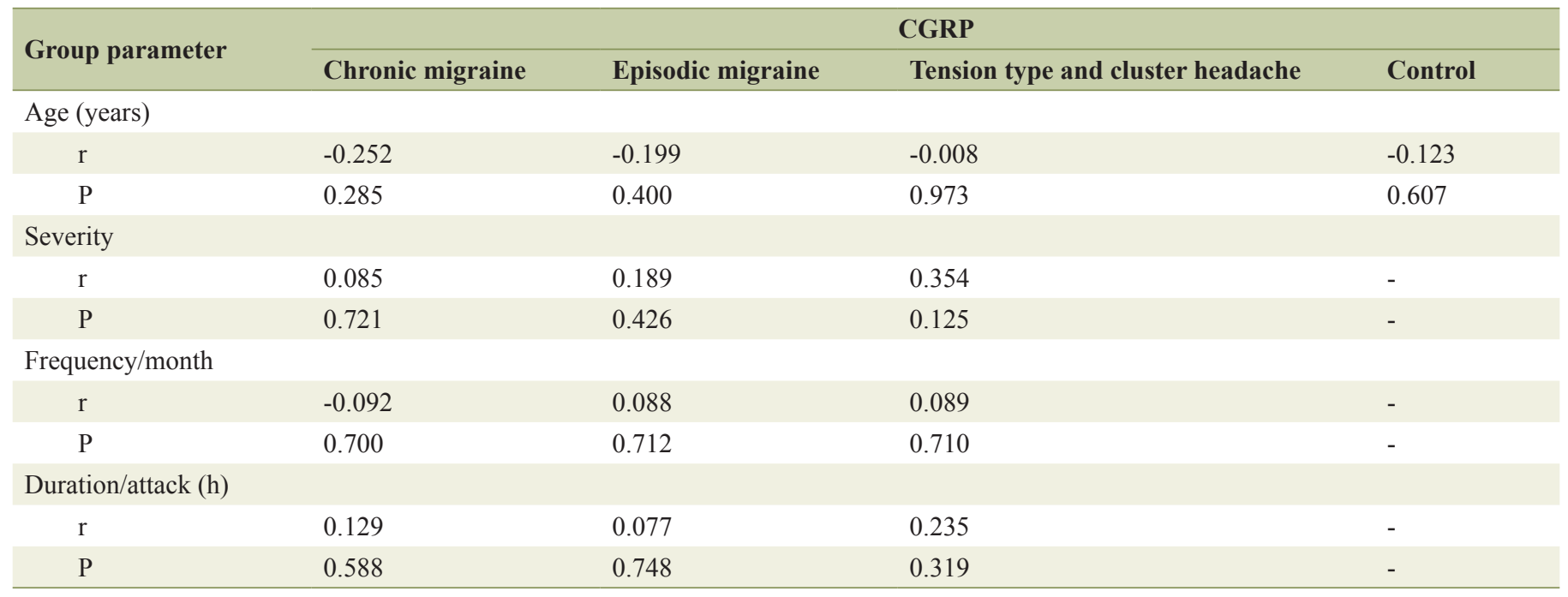

r: Pearson coefficient. 
workplace and the time between sampling and centrifugation has been considered as too prolonged, which, considering the rather short half-life of CGRP, would predict little neuropeptide left in the sample.

While Ashina et al [15] suggested that CGRP level remains elevated in migraineurs outside headache period as compared to controls, Tvedskov et al [18] did not find increased CGRP levels in the plasma during inter-episodic period.

The differences in the results could be due to the differences in the subject selection, source of blood sample (cubital versus jugular veins), and timing of blood sample collection after the last headache and other factors that affect CGRP levels. If samples are drawn very early in the attack, CGRP may not be elevated as it reaches to its peak $1.5 \mathrm{~h}$ of onset from migraine and normalizes by $6 \mathrm{~h}$ [19]. Also, these differences may be due to the presence of other factors that affect the plasma level of CGRP as obesity, intake of fatty meals and amount of exercise [20]. Almost all these studies are silent regarding these factors. Whether the blood was drawn from jugular vein or ante-cubital vein was a major issue. Since, migraine is primarily a cephalic neurovascular disorder, it was expected that CGRP concentration may be higher in the jugular blood than the peripheral blood. Previous studies have suggested that CGRP is increased in the internal as well as external jugular venous blood during headache. Whether the concentration is also increased in the peripheral blood is still debatable [15]. Jansen-Olesen et al [21] found that the level of CGRP in the external jugular blood and peripheral blood is significantly different on non-headache days, but not on the headache days in patients. Conversely, Ashina et al [22] proved that CGRP levels were nearly the same in both external jugular and anti-cubital veins either in the ictal or interictal periods. Thus, in light of conflicting evidences, it is difficult to discern whether CGRP concentration is different between the blood drawn from these two sources.

Although we are aware that the fact that, for ethical reasons, most of our patients with migraine were receiving daily preventive drugs, could be considered as a limitation of this study, it is also true that this could make our results even more evident because these drugs could reduce to some degree trigemino-vascular system activation and as a consequence decrease CGRP release.

To the limit of our knowledge, our study may be one of the few studies that compared between the plasma level of CGRP in other non-migrainous primary headaches as cluster headache and tension type headache. The significantly higher levels of CGRP that were found in migraineurs may suggest more specific association with the pathogenesis of migraine.

CGRP may have a role in both central and peripheral nervous system. In the central nervous system, CGRP may be involved in pain modulation, perception, and central sensitization [23]. It enhances the release of substance $P$ from primary afferent terminals. The transmission of nociceptive information that is induced by noxious stimuli may be potentiated by CGRP. It is also involved in modulating synaptic transmission of glutamate and acetylcholine $[24,25]$. In the periphery, release of CGRP from trigeminal fibers may lead to vasodilation and mast cell degranulation, with consequent persistent proinflammatory sensitization of trigeminal nociceptors [26].

CGRP may be involved in the pathogenesis of migraine through many ways. First, it may be related to the vasodilator phenomena of migraine as it is the most potent vasodilator peptide known and is particularly potent in intracranial arteries [27]. One study indicated that CGRP induces dilation of the middle cerebral artery and middle meningeal artery in migraineurs, coincident with induction of migraine [22], although this has not been found in other studies [28, 29]. Second, some researches postulated the endogenous release of CGRP during extracellular hyperkalemia-induced cortical spreading depression, and inhibition of this phenomenon by CGRP antagonists [30]. Third, CGRP may be involved in both neurogenic inflammation and peripheral sensitization of nociceptive neurons. It is a neuromodulator that can enhance synaptic transmission mediated by glutamatergic signaling [31]. Fourth, the CGRP plays a key role in light-aversive behavior, a common and important symptom in the diagnosis of migraine [32].

\section{Conclusion}

The peripheral CGRP levels at migraine attacks in the absence of symptomatic medication may be a potential biomarker for chronic migraine. This may open the door in the future for a new approach in treating migraine headaches by either inhibition of trigeminal CGRP release, or antagonism of CGRP receptors.

\section{References}

1. Murray CJ, Vos T, Lozano R, Naghavi M, Flaxman AD, Michaud C, Ezzati M, et al. Disability-adjusted life years (DALYs) for 291 diseases and injuries in 21 regions, 1990-2010: a systematic analysis for the Global Burden of Disease Study 2010. Lancet. 2012;380(9859):21972223.

2. Hawkins K, Wang S, Rupnow M. Direct cost burden among insured US employees with migraine. Headache. 2008;48(4):553-563.

3. Loder E. Triptan therapy in migraine. N Engl J Med. 2010;363(1):63-70.

4. Bigal ME, Walter S, Rapoport AM. Therapeutic antibodies against CGRP or its receptor. Br J Clin Pharmacol. 2015;79(6):886-895.

5. Silberstein SD, Holland S, Freitag F, Dodick DW, Argoff C, Ashman E. Evidence-based guideline update: Pharmacologic treatment for episodic migraine prevention in adults. Neurology. 2012;78(17):1337-1345.

6. Martelletti P. The therapeutic armamentarium in migraine is quite elderly. Expert Opin Drug Metab Toxicol. 2015;11(2):175-177.

7. Goadsby PJ, Silberstein SD, Dodick DW. Chronic daily headaches for clinicians. Hamilton: BC Decker Inc; 2005.

8. Goadsby PJ, Lipton RB, Ferrari MD. Migraine - current understanding and treatment. $N$ Engl $J$ Med. 2002;346(4):257-270.

9. Durham PL, Vause CV. Calcitonin gene-related peptide (CGRP) receptor antagonists in the treatment of migraine. CNS Drugs. 2010;24(7):539-548. 
10. Eftekhari S, Salvatore CA, Calamari A, Kane SA, Tajti J, Edvinsson L. Differential distribution of calcitonin generelated peptide and its receptor components in the human trigeminal ganglion. Neuroscience. 2010;169(2):683696.

11. Kaiser EA, Russo AF. CGRP and migraine: could PACAP play a role too? Neuropeptides. 2013;47(6):451-461.

12. Raddant AC, Russo AF. Calcitonin gene-related peptide in migraine: intersection of peripheral inflammation and central modulation. Expert Rev Mol Med. 2011;13:e36.

13. Cernuda-Morollon E, Larrosa D, Ramon C, Vega J, Martinez-Camblor P, Pascual J. Interictal increase of CGRP levels in peripheral blood as a biomarker for chronic migraine. Neurology. 2013;81(14):1191-1196.

14. Ho TW, Edvinsson L, Goadsby PJ. CGRP and its receptors provide new insights into migraine pathophysiology. Nat Rev Neurol. 2010;6(10):573-582.

15. Hansen JM, Hauge AW, Olesen J, Ashina M. Calcitonin gene-related peptide triggers migraine-like attacks in patients with migraine with aura. Cephalalgia. 2010;30(10):1179-1186.

16. Fusayasu E, Kowa H, Takeshima T, Nakaso K, Nakashima K. Increased plasma substance P and CGRP levels, and high ACE activity in migraineurs during headachefree periods. Pain. 2007;128(3):209-214.

17. Bigal ME, Walter S, Rapoport AM. Calcitonin gene-related peptide (CGRP) and migraine current understanding and state of development. Headache. 2013;53(8):12301244.

18. Tvedskov JF, Lipka K, Ashina M, Iversen HK, Schifter S, Olesen J. No increase of calcitonin gene-related peptide in jugular blood during migraine. Ann Neurol. 2005;58(4):561-568.

19. Sarchielli P, Alberti A, Codini M, Floridi A, Gallai V. Nitric oxide metabolites, prostaglandins and trigeminal vasoactive peptides in internal jugular vein blood during spontaneous migraine attacks. Cephalalgia. 2000;20(10):907-918.

20. Juhasz G, Zsombok T, Modos EA, Olajos S, Jakab B, Nemeth J, Szolcsanyi J, et al. NO-induced migraine attack: strong increase in plasma calcitonin gene-related peptide (CGRP) concentration and negative correlation with platelet serotonin release. Pain. 2003;106(3):461-470.
21. Jansen-Olesen I, Baun M, Amrutkar DV, Ramachandran R, Christophersen DV, Olesen J. PACAP-38 but not VIP induces release of CGRP from trigeminal nucleus caudalis via a receptor distinct from the PAC1 receptor. Neuropeptides. 2014;48(2):53-64.

22. Asghar MS, Hansen AE, Amin FM, van der Geest RJ, Koning P, Larsson HB, Olesen J, et al. Evidence for a vascular factor in migraine. Ann Neurol. 2011;69(4):635645.

23. Powell KJ, Ma W, Sutak M, Doods H, Quirion R, Jhamandas K. Blockade and reversal of spinal morphine tolerance by peptide and non-peptide calcitonin generelated peptide receptor antagonists. $\mathrm{Br} \mathrm{J}$ Pharmacol. 2000;131(5):875-884.

24. Marvizon JC, Perez OA, Song B, Chen W, Bunnett NW, Grady EF, Todd AJ. Calcitonin receptor-like receptor and receptor activity modifying protein 1 in the rat dorsal horn: localization in glutamatergic presynaptic terminals containing opioids and adrenergic alpha2C receptors. Neuroscience. 2007;148(1):250-265.

25. Seybold VS. The role of peptides in central sensitization. Handb Exp Pharmacol. 2009;194:451-491.

26. Ottosson A, Edvinsson L. Release of histamine from dural mast cells by substance $\mathrm{P}$ and calcitonin gene-related peptide. Cephalalgia. 1997;17(3):166-174.

27. Brain SD, Grant AD. Vascular actions of calcitonin gene-related peptide and adrenomedullin. Physiol Rev. 2004;84(3):903-934.

28. Levy D, Burstein R. The vascular theory of migraine: leave it or love it? Ann Neurol. 2011;69(4):600-601.

29. Goadsby PJ. The vascular theory of migraine - a great story wrecked by the facts. Brain. 2009;132(Pt 1):6-7.

30. Tozzi A, de Iure A, Di Filippo M, Costa C, Caproni S, Pisani A, Bonsi P, et al. Critical role of calcitonin generelated peptide receptors in cortical spreading depression. Proc Natl Acad Sci U S A. 2012;109(46):18985-18990.

31. Olesen J, Burstein R, Ashina M, Tfelt-Hansen P. Origin of pain in migraine: evidence for peripheral sensitization. Lancet Neurol. 2009;8:679-690.

32. Recober A, Kuburas A, Zhang Z, Wemmie JA, Anderson $\mathrm{MG}$, Russo AF. Role of calcitonin gene-related peptide in light-aversive behavior: implications for migraine. J Neurosci. 2009;29(27):8798-8804. 